\title{
The impact of mortality development on the number of centenarians in England and wales
}

\author{
George W. Leeson ${ }^{1}$ (D)
}

Published online: 20 September 2016

(c) The Author(s) 2016. This article is published with open access at Springerlink.com

\begin{abstract}
The world is ageing both at an individual and a population level, and population ageing is truly a global phenomenon. Life expectancies at birth have increased at the global level from 47 years in the mid-20th century to around 70 years today, and are expected to rise to 76 years by the mid- 21 st century. The proportion of the world's population aged 60 years and over has increased from $8 \%$ in the mid-20th century to $12 \%$, and by 2050 it is expected to reach $21 \%$. The emergence of large numbers of centenarians has accompanied this development. This paper outlines this emergence historically and the likely growth in the number of centenarians in the 21st century, in particular in England and Wales, analysing mortality trends since 1840 and the rise in the number of centenarians in the 20th and 21st centuries. The number of centenarians in England and Wales increased from around 160 in 1922 to almost 12,500 by 2012, but if mortality at all ages had remained constant from 1912 to 2012, then by 2012 the number of centenarians would only have been around 720 . By 2100 , the number of centenarians is expected to reach around 1.4 million, but if future mortality at all ages were to remain constant, then by 2100 the number of centenarians would be around 78,000. However, if predicted mortality for those aged 55 years and over was to decrease by an additional $5 \%$ every 5 years until 2100, then the number of centenarians in England and Wales would reach around 1.8 million by the end of the century.
\end{abstract}

Keywords Ageing populations · Radical life extension · Centenarians

George W. Leeson

george.leeson@ageing.ox.ac.uk

1 Oxford Institute of Population Ageing, University of Oxford, Oxford, UK 


\section{Introduction}

The populations of the world continue to age as fertility remains low (as in Europe and parts of Asia) or continues to decline (as in other parts of Asia, Latin America and some parts of Africa) and as mortality continues to decline at all ages (Leeson 2009, 2013, 2014a, 2014b). Population ageing-once regarded as an issue for the developed economies of Europe and North America-is becoming a truly global phenomenon as it now spreads across Latin America (Leeson 2013). The only notable exception is sub-Saharan Africa, which remains relatively young in demographic terms (United Nations 2015).

At the population level, the proportion of the world's population aged 60 years and over has increased from $8 \%$ and 200 million in the mid-20th century to $11 \%$ and almost 1 billion, and by 2050, it is expected to reach $22 \%$, corresponding to 2.1 billion people aged 60 years and over (United Nations 2015). This is a doubling of the population aged 60 years and over every 30 years between 1950 and 2040, after which growth slows.

The ageing of Europe's populations has been slower over this same period. The population aged 60 years and over in Europe increased from 65 million and $12 \%$ in 1950 to 132 million and $18 \%$ in 1990 - a 40 year doubling (United Nations 2015). By 2015, this had increased further to 176 million and $24 \%$, and is expected to peak around 2050 at 242 million and $34 \%$, short of a repeat 40 year doubling. In England and Wales too, ageing has been slower. According to data supplied by the Office for National Statistics in the United Kingdom, the population aged 60 years and over in England and Wales increased from 7 million and $16 \%$ in 1952 to 13 million and $23 \%$ in 2014, giving a doubling time of more than 60 years. By 2051, this population is expected to reach 20 million and $30 \%$.

At the individual level, life expectancies increased dramatically during the 20th century and are expected to continue to do so in the 21st century (United Nations 2015). Around the world, new generations can expect to live longer than previous generations, and the rate of increase is surprisingly strong and constant (Leeson 2014b). Life expectancies at birth for both sexes combined have increased at the global level from around 47 years in the mid-20th century to around 70 years today, and are expected to rise to around 77 years by the mid-21st century. In Europe these life expectancies have increased from 64 years in 1950 to around 76 years today, and are expected to reach around 82 years by the middle of the 21 st century. Data from the Human Mortality Database and the Office for National Statistics reveal that life expectancies at birth in England and Wales increased from 48 years for females and 44 years for males in 1900 to 71 years and 66 years respectively by 1965 , and again to 84 and 80 years respectively in 2014 .

Life expectancies increased dramatically during the first half of the 20th century, and then more modestly in the latter half of that century as a result of improvements in survival at older ages (Fries 1980; Leeson 1981, 1982, 2014a; Vaupel 1998). Furthermore, there is a body of evidence indicating that lives will continue to be extended (Bongaarts 2006; Thatcher 1999, 2001; Olshanky et al. 2001; Robine et al. 2003; Wilmoth and Robine 2003; Christensen et al. 2009; Vaupel 2010; Leeson 
2011, 2014a). There is strong historical evidence to support this future, as pointed out by Oeppen and Vaupel (2002), inasmuch as female life expectancy at birth in the longest-lived country at any time has increased year on year since 1840 at a rate of approximately 2.5 years per decade, and the same is true, but at a slower rate, for males (Westendorp 2004).

Historically, there has been scepticism about the limit to longevity, moving from a belief in limits to life-span to a belief in a limit to life expectancy. In 1928, for example, it was predicted that the limit to life expectancy was 64.75 years for both males and females (Dublin 1928). However, unbeknown to Dublin, these limits had already been surpassed in New Zealand. In 1990, Olshansky et al. (1990: 638) suggested "...that life expectancy should not exceed...35 years at age 50 unless major breakthroughs occur in controlling the fundamental rate of aging". This limit was exceeded in 2014 by the Japanese population with life expectancy at age 50 reported as 35.16 (Japanese Mortality Database, National Institute of Population and Social Security Research, Tokyo).

This paper will present by way of introduction an overview of the emergence of centenarians in various countries and the reliability of data on long lives. It then moves to focus on the emergence of centenarians-and the demographics underlying this development-in England and Wales. The contribution of declining mortality to the growth in the number of centenarians in the 20th century is analysed, and the potential for even greater increases in the number of people living to 100 years and beyond in the 21 st century is also investigated.

\section{The emergence of (large numbers of) centenarians}

Data from the Office for National Statistics and the Human Mortality Database indicate that the number of people aged 100 years and over in England and Wales increased from less than 200 in 1922 to 570 in 1961 . By 1981 it had climbed to 2418 and to 12,318 in 2012. Elsewhere, similar growth in the number of extremely longlived people was occurring. In Japan, for example, the number of centenarians increased from 154 in 1963 to almost 18,000 in 2002 (Robine et al. 2003).

Centenarians-or at least claims of centenarians-are not new, although verifiable ages at death prior to the 19th century are increasingly difficult to identify as records were unreliable even if they existed. The Greek philosopher Democritus of Abdera is referenced by Diogenes Laertius in 250AD as 'assuredly' having lived 109 years. The longest-lived person in the Bible was Methuselah who lived to 969 years old (Genesis 5:27), just 7 years longer than Jared who lived 962 years (Genesis 5:20). Indeed the Bible includes many people living for at least 100 years and some living several hundred years. This extended and fanciful longevity is probably symbolic of their influence rather than their actual physical length of life.

According to Jeune (1994), centenarians did not exist before 1800 in any population or in any period of world history, an interesting claim in that his main argument is that there are no reliable records. One could claim that this lack of evidence (in the form of birth and death records) equally does not completely dismiss the possibility of centenarians or even supercentenarians (persons aged 
110 years and over) at any time in history and in any population. In fact, in Norway, there does seem to be evidence of a centenarian before 1800 (Kjaergaard 1995).

By the 19th century, with improving and more universal records of births and deaths in many countries, one would assume that evidence of centenarians becomes more readily and reliably available. Many of the claims to such longevity in Europe and North America, however, have been refuted, as they cannot be verified beyond doubt (Jeune and Vaupel 1999).

The registration of vital events is a pre-requisite for reliable evidence, particularly about extremely long lives. The origin of vital statistics in the modern sense can be traced to an analysis of the English bills of mortality published by the father of demography John Graunt in 1662 as Natural and political observations mentioned in the following index, and made upon the bills of mortality (Sutherland 1963). Death by social class was not recorded in England until 1921 (Caselli 1991).

The earliest systems of vital registration were established in Finland (1628), Denmark (1646), Norway (1685) and Sweden (1686). In England and Wales, socalled parochial registration of baptisms and burials began as early as 1538. Some years after Graunt's work, an act was passed in 1694 providing for the registration of births and deaths throughout the country. However, this was not widely successful and estimates of population in England and Wales in the eighteenth century must rely on the parochial registers until the system of civil registration was established in 1836. This act, however, did not impose penalties for failure to comply and this was not addressed until 1874.

Vital event registration would suggest more reliable and complete information. However, a recent case from Japan revealed this is not always so (The Guardian, 12 August 2010). Japanese authorities admitted that almost 200 people registered as aged 100 years or over were missing. Officials in Kobe had lost track of 105 of the city's then 847 centenarians, and in Osaka, 64 of 857 centenarians had been lost-in fact, it turned out that one of them, a man registered as 127 years old, had died as long ago as 1966.

The verified oldest person ever to have lived is Jeanne Calment, who died in France in 1997 aged 122 years and 164 days. The verified oldest person still alive (as of 16 May 2016) is Emma Morano of Italy-a youngster at 116 years. The oldest verified person in the United Kingdom was Charlotte Hughes, who died in 1993 aged 115 years and 228 days. The oldest living person in the United Kingdom as of 16 May 2016 was Gladys Hooper aged 113 years and 120 days. The last surviving Briton born in the 19th century was Grace Jones who died on 14 November 2014. Living in three centuries is nothing new. Margaret Neve lived in the 18th, 19th and 20th centuries (1792-1903) and is one of the earliest verified of such cases, and large proportions of those born towards the end of the 20th century will live into the 22nd century (Office for National Statistics 2012b; Department for Work and Pensions 2011).

The highest reported reliable age at death globally is thus well over 100 years and even over 110 years, and has been increasing. Estimates from the Office for National Statistics support this for England and Wales too. From the 1960s to the late 1990s in England and Wales, the highest verified age at death has increased from 109 to 115 years (Thatcher 1999, 2001). 
There is thus considerable evidence that reflects the demographic reversal of the previous conviction that mortality at older ages is intractable (Wilmoth 1997; Vaupel 1998; Leeson 2014a). Indeed, declines in mortality among the extreme aged-particularly females-have been noteworthy, and improvements among males, albeit more modest, have also occurred in the second half of the 20th century (Kannisto 1994, 1996; Kannisto et al. 1994; Vaupel 1998).

This and the underlying demographic have led to significant increases in the numbers of centenarians around the world. Figure 1 shows the increase in centenarians for selected countries in Europe and North America along with Japan from 1937 to 2012. It reveals how the speed and timing of these increases has varied across countries - indeed the number of centenarians in Bulgaria actually declined from 559 in 1947 to 159 in 1997, and today has re-attained its late 1960s level of 444 centenarians.

The numbers of centenarians in England and Wales, Sweden, Japan and France in the 1930s and until the late 1940s were between 40 and 220, but from the early 1950s the numbers in England and Wales and in France began more or less doubling every decade right up until 2012, corresponding to the decade-doubling results of Vaupel and Jeune (1995) in respect of low mortality countries from 1960 to 1990. This decade-doubling did not happen in the United States, however, nor in Sweden except in the 1970s/early 1980s. The case of Japan is interesting because of both the timing and speed of the increase in the number of centenarians-almost doubling from 86 in 1947 to 158 in 1962 and then rising steeply at more than decadedoubling intensity to more than 45,000 in 2012, overtaking and leaving France behind by the late 1990s. Less clear from Fig. 1 is the case of Bulgaria, which as pointed out above experienced an absolute decline in the number of centenarians throughout the Soviet era, finally picking up in the late 1990s.

Although the rate of ageing in England and Wales has been slower in more recent decades as discussed above, other elements have emerged as part of this population ageing, namely the increasing number of centenarians and even supercentenarians,

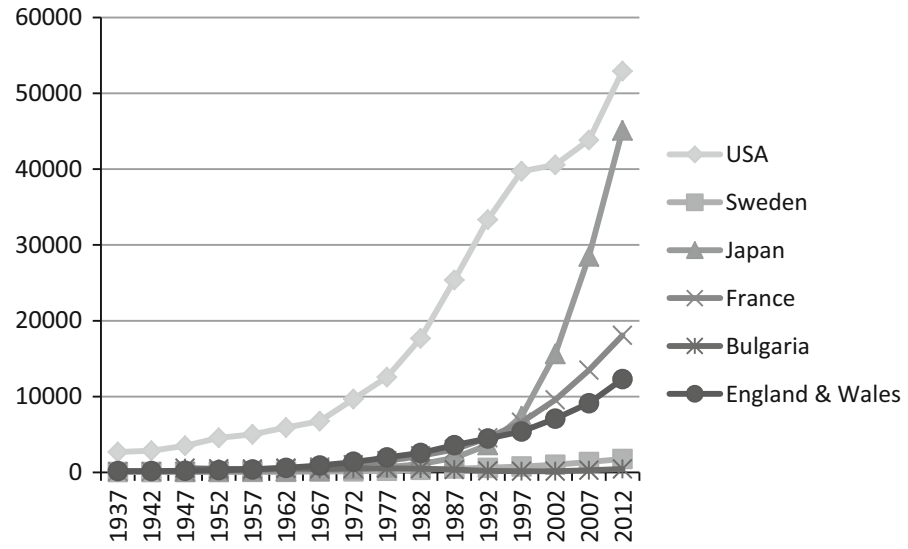

Fig. 1 The number of centenarians in selected countries, 1937-2012. Source: Human Mortality Database and Office for National Statistics 
the number of whom has increased from 0 in 1922 (Human Mortality Database) to 16 in 2012 (Office for National Statistics).

Centenarians are not unique to the more developed economies of the world, as is evident from Table 1, which provides data for three large developing countries and for Sub-Saharan Africa. The centenarian experience is different from that in the developed economies illustrated in Fig. 1, beginning with relatively low numbers in absolute terms but increasing quite dramatically over two decades from 1990 to 2010. For example, Brazil has seen its centenarian population increase from around 3000 in 1990 to around 34,000 in 2010, surpassing by then that of India which had had around four times as many centenarians as Brazil in 1990. The centenarian population in China has also begun to increase, but is still only around one-third of those of Brazil and India. In the meantime, centenarians in the whole of sub-Saharan Africa remain exceptionally low, which is not surprising in a continent where life expectancy at birth is still struggling to pass the 60-year mark (United Nations 2015).

Across much of the globe then, centenarian populations have increased from "handfuls" to thousands as mid- and late- and extreme late-life mortality have all decreased. This development and the drivers behind it will now be considered in more detail in the specific case of England and Wales.

\section{Mortality development in England and Wales since circa 1840}

In the latter part of the 19th century, the absolute number of deaths per year registered in England and Wales increased from around 350,000 in the middle of the century to around 600,000 by the end of the century. The number then peaked in 1918 at just over 610,000, after which deaths in absolute terms declined to around 440,000 in 1923, then trended generally upward as the ageing of the population gained momentum, although in recent years the number has fallen below 500,000 per annum (Leeson 2014b). By 2011, the number of deaths in the population was just over 484,000, corresponding to a CDR of 8.8 per 1000 population-the lowest recorded for England and Wales (Office for National Statistics 2012a). Over this same period life expectancy at birth increased from around 40 years in 1841 to around 50 years by the turn of the 20th century, and then to around 70 years by the 1950s and around 80 years at present (Fig. 2). From these data, the time taken for 10 year incremental increases in life expectancy at birth for both males and females since 1841 decreased dramatically initially, but has since been more prolonged. The first ten-year increase for females took around 60 years and for males almost

Table 1 Numbers of centenarians in Brazil, India, China and sub-Saharan Africa, 1990-2010. Source: United Nations (2013)

\begin{tabular}{rrrrl}
\hline & Brazil & India & China & Sub-Saharan Africa \\
\hline 1990 & 3000 & 13,000 & 4000 & 1000 \\
1995 & 6000 & 14,000 & 7000 & 1000 \\
2000 & 12,000 & 19,000 & 8000 & 1000 \\
2005 & 21,000 & 24,000 & 9000 & 1000 \\
2010 & 34,000 & 33,000 & 10,000 & 2000 \\
\hline
\end{tabular}




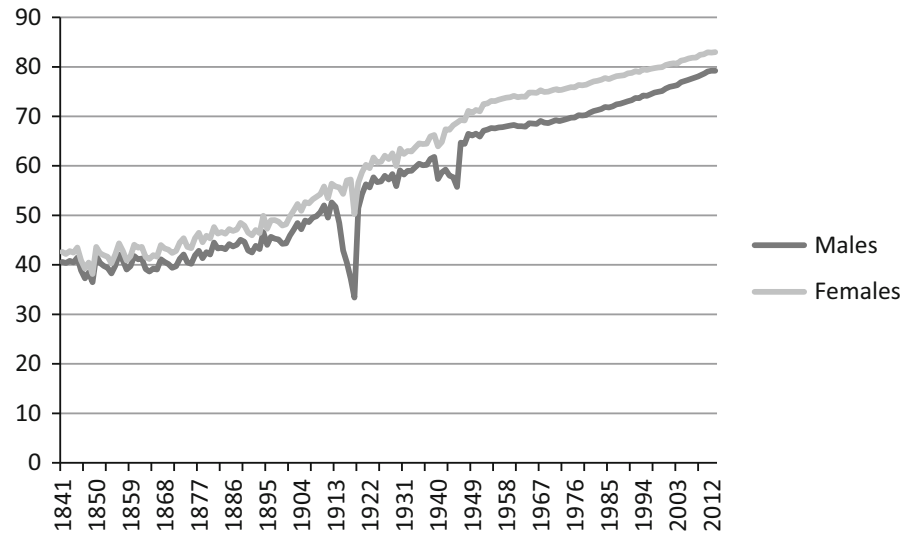

Fig. 2 Life expectancy at birth for males and females in England and Wales, 1841-2013. Source: Leeson 2014b and Human Mortality Database

70 years; the second took just over 20 years for females and just over 25 years for males; the third increase took around 26 years for females but more than 40 years for males; and while the fourth 10 year increase for females took almost 60 years, it had still not quite been achieved for males by 2013. This reflects in part the transition from juvenile to senescent mortality reduction and the increasing difficulty associated with adding years to life expectancy at birth when these years are added in later life rather than in early life (Bongaarts 2006).

The difference in male and female life expectancy at birth is showing signs of convergence, having increased from approximately 2 years in the 1840 s to 1870 s to approximately 3 years until the early 1900s, after which it increased to 4 years and then to a 6 year difference in the 1960s. In the 1990s, male and female life expectancies began to converge, the difference falling to approximately 5 years in the 1990 s and to less than 4 years by the 2010 s.

As can be seen from Fig. 2, life expectancies at birth for both males and females increased by 20 years in the first 50 years of the 20th century (a $43 \%$ increase for males and a $42 \%$ increase for females), from around 50 years at the turn of the century to around 70 years in the early 1950s. It will take 100 years from 1950 to 2050 to increase these life expectancies at birth by another 20 years, corresponding to only a $29 \%$ increase for males and a $23 \%$ increase for females (Leeson 2014b).

As previously mentioned, recent late-life declines in mortality reflect the demographic reversal of the previous conviction that mortality at older ages was intractable (Wilmoth 1997; Vaupel 1998). In fact, declines in mortality among the extreme aged have been significant (Vaupel 1998; Kannisto 1994, 1996; Kannisto et al. 1994). Figure 3 shows that life expectancy at age 65 years in England and Wales remained at around 10-12 years from 1841 until the early 20th century, and the difference between male and female life expectancy at age 65 was less than 1 year. From the beginning of the 20th century, however, life expectancy at age 65 began a steady and consistent trend upwards, from around 10-12 years to around 18-21 years at present. With this trend came a divergence of male and female life 


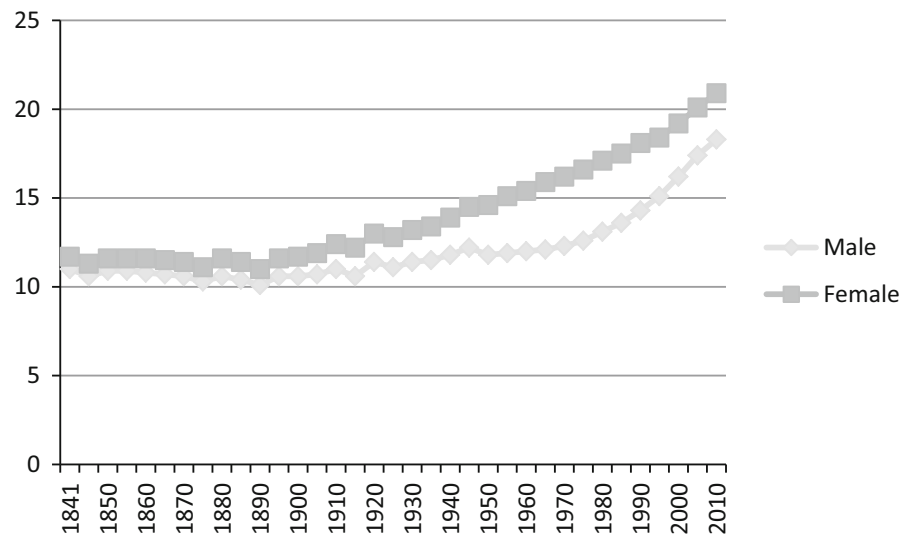

Fig. 3 Life expectancy at age 65 for males and females in England and Wales, 1841-2010. Source: Leeson 2014a

expectancies at age 65 in the 21st century. It is interesting to note, however, that the trend, albeit upward, differs for males and females. After the Second World War the increase in life expectancy at age 65 for females remained steady, while the increase for males began to slow, so that the male-female difference in life expectancy at this age increased to around 4 years by the mid-1980s. From around the mid-1980s, however, male life expectancy at age 65 increased more steeply than that for females, and the difference has been reduced to approximately 2.5 years. One hundred and seventy years had seen late-life life expectancy increase by just over 7 years for males and almost 9 years for females - quite an achievement given the entrenchment of the belief that late-life mortality was a constant.

The last 50 years in England and Wales have seen for both males and females an approximate 10 year shift in mortality levels for those aged 50 years and over, as is illustrated in Table 2 which shows current ages (50, 60, 70, 80 and 90 years) and ages of equivalent mortality 50 years ago for males and females in England and Wales. Thus, 50 years ago, those aged around 40 years in England and Wales had an age-specific mortality equivalent to that of people aged around 50 years at present; those aged around 50 years had an age-specific mortality equivalent to that of people aged around 60 years at present and so on. This is part of the so-called rectangularisation of survivorship (Fries 1980).

Table 2 Current ages and the ages of equivalent mortality 50 years ago for males and females in England and Wales. Source: Own calculations from ONS data

\begin{tabular}{llllll}
\hline & 50 & 60 & 70 & 80 & 90 \\
\hline Males & 42 & 51 & 59 & 70 & 83 \\
Females & 41 & 52 & 62 & 72 & 83 \\
\hline
\end{tabular}




\section{Centenarians in England and Wales, 1922-2012}

As outlined above, these declines in mortality in England and Wales from the middle of the 19th century drove up life expectancies at birth in particular, but also life expectancies later in life, although these were slower and later to begin their increase. These developments meant that the potential was being accumulated for the rise in the number of centenarians in England and Wales illustrated in Fig. 1, with the number eventually doubling more or less every decade after 1960. But-as with other mortality indicators - the difference between the number of male and female centenarians over time is striking, as can be seen from Fig. 4.

In 1922, there were just 36 male centenarians in England and Wales. This number fluctuated moderately between 24 and 48 until 1958, when a continual increase began. From 1958 to 1970, the number of male centenarians increased from 48 to 144 by 1970 , doubling to 288 by 1980 . The next doubling took almost 20 years as the number reached 600 male centenarians in 1999. It then took only 9 years to 2008 to double again to 1198 male centenarians, and by 2012, there were 1780 male centenarians in England and Wales.

The growth in the number of female centenarians in England and Wales was similar, albeit at a higher level at every point in time after 1922. In 1922 the number of female centenarians was more than triple the number of male centenarians, namely 126, and this number fluctuated moderately between 110 and 147 for about 25 years. However, the continual increase in the number of centenarians began earlier for females than for males in 1946, when the number increased from 142 in 1945 to 174 . By 1957 this had doubled to 347, and it then doubled again to 692 in 1965. This pace of doubling continued, the number reaching 1397 in 1974, then 2733 in 1985 and 5564 in 2000. By 2012 there were 10,538 female centenarians in England and Wales, six times the number of male centenarians.

Of course the number of centenarians is determined by the complete demography of the past-i.e. the size of birth cohorts and the developments in age-specific

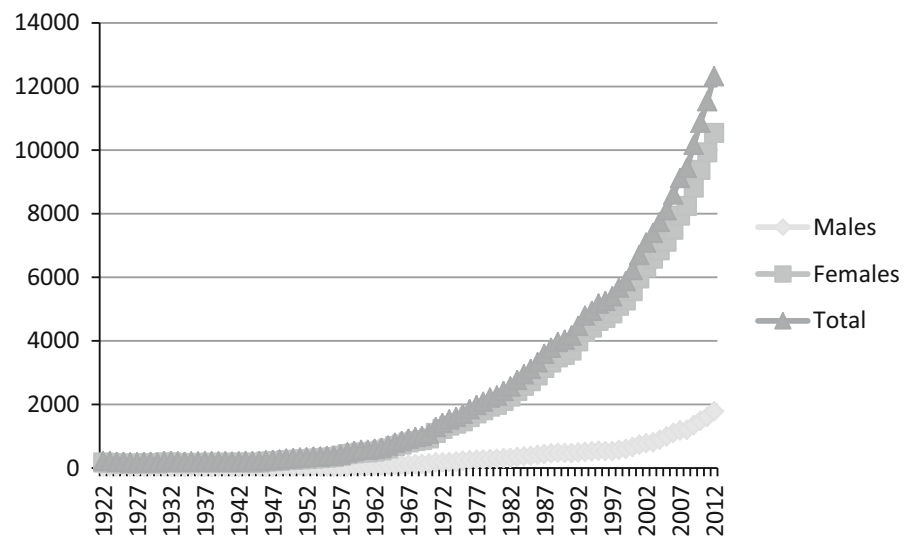

Fig. 4 Numbers of centenarians in England and Wales by sex, 1922-2012. Source: 1922-1961, Human Mortality Database; 1961-2012, data provided by Office for National Statistics 
mortality as cohorts age, along with any migration. Those who had reached 100 years and more in 2012 were the survivors of those born in 1912 and earlier. There is an indication from data on births (Leeson 2014b) that the fertility effect is limited as the annual number of live births remains at around 900,000 from 1880 to 1912 , but it is possible to determine the effect of declining mortality on the number of centenarians.

If it is assumed that mortality at all ages remained constant from 1922 to 2012, then the number of centenarians in England and Wales would have increased much more modestly over time than is illustrated in Fig. 4. By 2012 the number of male centenarians would only be around 120 , and the number of female centenarians would stand at just over 600 . This is illustrated in Table 3 for selected years from 1922 to 2012. In other words, the mortality declines of the period 1922-2012 resulted in almost 17 times more centenarians than there would have been had mortality not declined during the 90 -year period.

\section{Centenarians in England and Wales, 2010-2100}

What of the future? Can we expect the trends of the last 170 years or so-with increasing life expectancies at birth and at age 65 , for example-to continue into the future? How will the changes in life expectancy affect the number of centenarians moving further into and through the 21 st century? And what if late-life mortality improves even more than official forecasts suggest? This final section considers the expected increase in the number of centenarians, and the growth possible with even more dramatic decreases in late-life mortality.

Data from the Office for National Statistics reveal that by the turn of the next century, life expectancies at birth are predicted to be 93 years for males and 95.6 years for females in England and Wales, while at age 65 years, life expectancies are expected to be 29.9 years for males and 31.1 years for females. The survival curves, in other words, are expected to continue to rectangularise (Fries

Table 3 Numbers of centenarians in England and Wales by sex, 1922-2012, selected years, observed and assuming constant mortality from 1922. Source: own calculations from Human Mortality Database data

\begin{tabular}{lrrrrrrrrrr}
\hline & 1922 & 1932 & 1942 & 1952 & 1962 & 1972 & 1982 & 1992 & 2002 & 2012 \\
\hline Males & & & & & & & & & & \\
Observed & 36 & 29 & 33 & 44 & 76 & 180 & 314 & 484 & 778 & 1780 \\
Constant & 36 & 29 & 35 & 44 & 59 & 76 & 90 & 91 & 99 & 117 \\
Females & & & & & & & & & & \\
Observed & 126 & 146 & 141 & 260 & 522 & 1229 & 2246 & 3982 & 6312 & 10,538 \\
Constant & 126 & 146 & 195 & 249 & 323 & 417 & 515 & 549 & 580 & 615 \\
Total & & & & & & & & & & \\
Observed & 162 & 175 & 174 & 304 & 598 & 1409 & 2560 & 4466 & 7090 & 12,318 \\
Constant & 162 & 175 & 230 & 293 & 382 & 493 & 605 & 640 & 679 & 732 \\
\hline
\end{tabular}


1980), which will lead to increasing numbers of people at extreme ages, including centenarians, as is reflected in the official forecasts of the Office for National Statistics. Figure 5 illustrates the projected numbers of centenarians in England and Wales across the remainder of the 21 st century.

In 2010, centenarians in England and Wales numbered around 11,000 (1500 males and 9500 females). As can be seen from Fig. 5, this number is projected to increase steadily until the end of the 21 st century (albeit with slower increases in the 2070s for both males and females and at the end of the century for females). In addition, the relative difference between male and female numbers is expected to decrease. In 2010, there are five times as many female as male centenarians, but by 2100 numbers of male and female centenarians are expected to reach around 620,000 and 776,000 respectively; just $25 \%$ more female than male centenarians. This corresponds to an absolute growth of almost 15,500 centenarians per year over the period 2010-2100. Doubling times for the number of centenarians are expected to be around 10 years in the first half of the century, rising to $15-25$ years in the second half.

Of course, the number of projected centenarians will again be determined by the complete demography of the future-i.e. the sizes of existing cohorts and developments in age-specific mortality as cohorts age, along with any migration. Those projected to reach 100 years and more in 2100 will be the survivors of those aged at least 10 years in 2010 .

A scenario with projected mortality at all ages remaining constant from 2010 to 2100 would see the number of centenarians in England and Wales increase significantly more modestly than is illustrated in Fig. 5. The number would, however, still increase seven-fold from 2010 to 2100 taking the number of male centenarians to around 32,000 and the number of female centenarians to around 46,000.

On the other hand, age-specific later-life mortality may decline more than projected in the official forecasts of the number of centenarians. From the $1960 \mathrm{~s}$ to the late 1990 s, the highest verified age at death in England and Wales ranged from

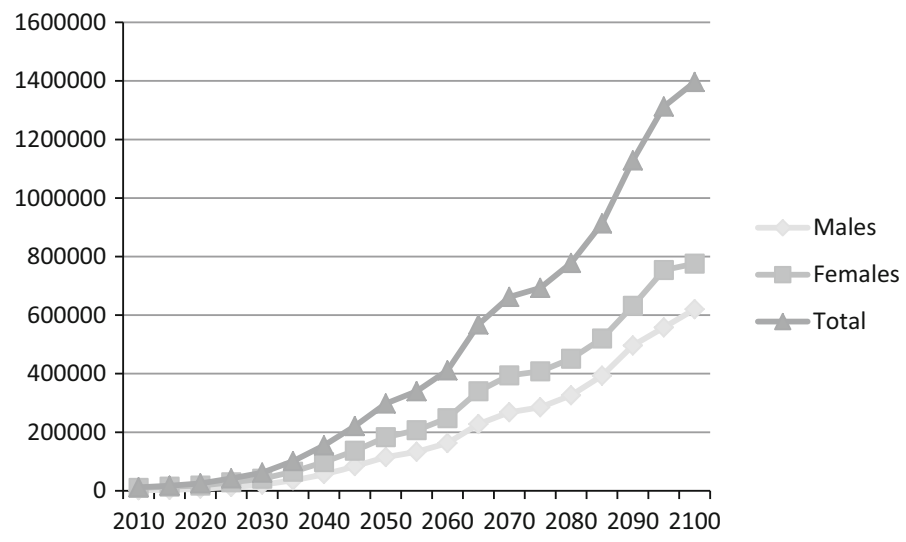

Fig. 5 Projected numbers of centenarians in England and Wales, 2010-2100. Source: Data provided by Office for National Statistics 
109 to 115 years. Projected death rates would mean that the highest ages being reached in the 2080s will be 116 to 123 years (Leeson 2014b; Thatcher 1999). It is also the case that the maximum recorded life expectancies at birth (in any country) for males and females from 1840 have increased year on year at a rate of approximately 2.5 years per decade - at a slightly slower rate for males (Westendorp 2004).

Consider finally a scenario in which projected mortality for those aged 55 years and over decreases by an additional $5 \%$ every 5 years in relation to the official projected mortality.

The number of centenarians in England and Wales by 2100 would reach around 1.8 million. This additional $5 \%$ decline scenario is based primarily on the observed decreases in mortality for those aged 55 years and over in the previous 90 years from 1910-19 to 2000-2009, where mortality of females aged 55-79 years declined on average every 5 years by between around 3 and $5.5 \%$. For males, declines amounted to between 2.5 and $4 \%$. The more optimistic scenario, however, is fuelled by potential additional decreases brought about by medical advances, such as stem cell therapies enabling 80-year olds to live to 200 years of age (Lavasani 2012).

In both scenarios-no change in mortality and greater-than-projected decreases in later-life mortality - the impact on the number of centenarians is marked. Table 4 illustrates the three different scenarios of centenarian increase from 2010 to 2100 .

\section{Concluding remarks}

This paper has outlined the emergence of centenarians historically and the development in the number of centenarians in the 21st century, in particular in England and Wales, analysing mortality since 1840 and the growth and likely future

Table 4 Numbers (thousands) of centenarians in England and Wales by sex, 2010-2100, selected years, projected and assuming (1) constant mortality from 2010 to 2020, and (2) an additional $5 \%$ decrease in the projected mortality every 5 years among those aged 55 years and over. Source: official projections and own calculations

\begin{tabular}{lrrrrrrrrrr}
\hline & 2010 & 2020 & 2030 & 2040 & 2050 & 2060 & 2070 & 2080 & 2090 & 2100 \\
\hline Males & & & & & & & & & & \\
Projected & 2 & 7 & 21 & 57 & 115 & 163 & 268 & 326 & 496 & 620 \\
Constant & 2 & 7 & 14 & 18 & 24 & 25 & 30 & 27 & 31 & 32 \\
Decreasing & 2 & 9 & 28 & 74 & 147 & 216 & 327 & 392 & 584 & 918 \\
Females & 10 & 18 & 41 & 98 & 183 & 248 & 394 & 451 & 632 & 776 \\
Predicted & 10 & 18 & 26 & 29 & 37 & 39 & 46 & 42 & 46 & 46 \\
Constant & 10 & 24 & 56 & 124 & 227 & 310 & 469 & 534 & 734 & 879 \\
Decreasing & 10 & & & & & & & & & 1396 \\
Total & 12 & 25 & 62 & 155 & 298 & 411 & 662 & 778 & 1128 & 1396 \\
Predicted & 12 & 25 & 40 & 47 & 61 & 64 & 76 & 69 & 77 & 78 \\
Constant & 12 & 33 & 84 & 198 & 374 & 526 & 796 & 926 & 1318 & 1797 \\
Decreasing & 12 & & & & & & & & & \\
\hline
\end{tabular}


growth in the number of centenarians in the 20th and 21st centuries. Both the historical and future analyses investigate the effects of both declining and constant mortality on the number of centenarians, indicating that the 21 st century will indeed be a century of centenarians.

The transition in England and Wales has been outlined, from a demography of low life expectancy and few centenarians in the mid-19th century to one of increasing life expectancies and an increasing but still relatively modest number of centenarians in the 20th century, and into the 21 st century as one with the number of centenarians increasing from around 12,000 in 2010 to around 1.4 million and perhaps even 1.8 million by 2100 . The power of declining later-life mortality is captured in both the retrospective and the prospective analyses.

If it is assumed that mortality at all ages had remained constant from 1922 to 2012, the number of centenarians in England and Wales would have increased from 162 in 1922 to 732 in 2012, compared with the actual increase to more than 12,000.

Similarly, if it is assumed that mortality at all ages will remain constant from 2010 to 2100 the number of centenarians in England and Wales would increase from around 12,000 to around 78,000 compared with the predicted increase to almost 1.4 million. And if projected mortality for those aged 55 years and over decreases by an additional $5 \%$ every 5 years in relation to projected mortality, the number of centenarians would reach around 1.8 million. This trend is a natural consequence of ongoing demographic change in England and Wales and elsewhere, but is society prepared for this century of centenarians and its impact on individuals, families, communities and society at large?

European populations were surprised by the fundamental changes brought about by the ageing of their populations in the latter part of the 20th century-a combination of demographic resistance to the idea that human longevity could exceed expectations and the decline in mid- and late-life mortality as the prevention and treatment of lifestyle diseases, such as cardiovascular diseases, improved. The result was that old age was pushed to age 80 and over.

The future will also present surprises and challenges if the evidence is ignored of the significantly increasing number of extreme-aged individuals in our societies, with centenarians comprising increasing numbers and proportions of populations, and with old age being pushed back even further.

While this paper has England and Wales as its focus, the century of centenarians will be at least equally challenging elsewhere in both the developed and the emerging economies of the world. Regardless of location, the trend has fundamental consequences for the way in which individuals view and live these extending lives, but also for the way in which societal infrastructures (education, workplace, housing, transport, health and social care) will need to be adapted to the needs of these extreme-aged populations.

How could/should people begin to prepare themselves for such long lives? At the individual level the trend presents a challenge to life course planning. It is also a challenge to current concepts of old age and retirement (is retirement even at age 75 years sustainable?). Family dynamics will be challenged by the survival of these extreme-aged generations delaying intergenerational succession and inheritance and depending on smaller families for support in frail and dependent old age. The 
prospect of declining population size as well as this new demography of centenarians raises even more and different issues as workforces contract.

Open Access This article is distributed under the terms of the Creative Commons Attribution 4.0 International License (http://creativecommons.org/licenses/by/4.0/), which permits unrestricted use, distribution, and reproduction in any medium, provided you give appropriate credit to the original author(s) and the source, provide a link to the Creative Commons license, and indicate if changes were made.

\section{References}

Bongaarts, J. (2006). How long will we live? Population and Development Review, 32(4), 605-628.

Caselli, G. (1991). Health transition and cause-SPECIFIC mortality. In R. Schofield, D. Reher, \& A. Bideau (Eds.), The decline of mortality in europe. Oxford: Clarendon Press.

Christensen, K., Doblhammer, G., \& Vaupel, J. (2009). Ageing populations: the challenges ahead. Lancet, 374(9696), 1196-1208.

Department for Work and Pensions. (2011). Number of future centenarians by age group. London: Department for Work and Pensions.

Dublin, L. I. (1928). Health and wealth. New York: Harper.

Fries, J. F. (1980). Aging, natural death and the compression of morbidity. The New England Journal of Medicine, 303(3), 130-135.

Jeune, B. (1995). In search of the first centenarians. In B. Jeune \& J. W. Vaupel (Eds.), Exceptional longevity: from prehistory to present Odense monographs on population ageing 2. Odense: Odense University Press.

Jeune, B., \& Vaupel, J. M. (1999). Species of evidence of exceptional longevity. In B. Jeune \& J. W. Vaupel (Eds.), Validation of exceptional longevity Odense monographs on population Ageing 6. Odense: Odense University Press.

Kannisto, V. (1994). Development of oldest-old mortality, 1950-1990. Odense: Odense University Press.

Kannisto, V. (1996). The advancing frontier of survival: life tables for old age. Odense: Odense University Press.

Kannisto, V., Lauritsen, J., Thatcher, R., \& Vaupel, J. (1994). Reductions in mortality at advanced ages. Population and Development Review, 20(4), 793-810.

Kjaeregaard, T. (1995). Alleged Danish centenarians before,1800. In B. Jeune \& J. W. Vaupel (Eds.), Exceptional longevity: from prehistory to present. Odense monographs on population ageing 2. Odense: Odense University Press.

Lavasani, M., et al. (2012). Muscle-derived stem/progenitor cell dysfunction limits health span and lifespan in a murine progeria model. Nature Communications,. doi:10.1038/ncomms 1611 .

Leeson, G. W. (1981). Ældres dødelighed 1960-1980 (The mortality of older people in Denmark, 1960-80). Ugeskrift for Laeger, 143, 2324-2327.

Leeson, G. W. (1982). Demographic ageing in Denmark in the 20th century. The Eugenics Society Bulletin, 14, 46-52.

Leeson, G. W. (2009). Demography, politics and policy in Europe. In P. Ludlow (Ed.), Setting EU priorities 2009 (pp. 102-124). Ponte de Lima: The European Strategy Forum.

Leeson, G. W. (2011). Prepared or not, Latin America faces the challenge of aging. current history. Journal of Contemporary World Affairs 110, 733, 75-80.

Leeson, G. W. (2013). The demographics of ageing in Latin America, the Caribbean and the Iberian Peninsula, 1950-2050. In V. Montes de Oca (Ed.), Envejecimiento-en America Latina y elCaribe (pp. 53-71). Mexico: UNAM.

Leeson, G. W. (2014a). Future prospects for longevity. Post Reproductive Health, 20(1), 17-21.

Leeson, G. W. (2014b). Increasing longevity and the new demography of death. International Journal of Population Research, doi:10.1155/2014/521523.

Oeppen, J., \& Vaupel, J. (2002). Broken limits to life expectancy. Science, 296, 1029-1031.

Office for National Statistics. (2012a). Annual mid-year population estimates for England \& Wales, statistical bulletin. London: Office for National Statistics. 
Office for National Statistics. (2012b). Deaths registered in England and Wales (series DR), 2011, statistical bulletin. London: Office for National Statistics.

Olshansky, J., Carnes, B. A., \& Cassel, C. (1990). In search of Methusela: estimating the upper limits to human longevity. Science, 50(4981), 634-640.

Olshansky, J., Carnes, B. A., \& Desesquelles, A. (2001). Prospects for human longevity. Science, 291(5508), 1491-1492.

Robine, J.-M., Saito, Y., \& Jagger, C. (2003). The emergence of extremely old people: the case of Japan. Experimental Gerontology, 38, 735-739.

Sutherland, I. (1963). John Graunt: a tercentenary tribute. Journal of the Royal Statistical Society, 126(4), 537-556.

Thatcher, R. (1999). The demography of centenarians in England and Wales population trends. London: Office for National Statistics.

Thatcher, R. (2001). The demography of centenarians in England and Wales. Population; An English Section, 13(1), 139-156.

United Nations. (2013). World population prospects: 2013 revision. New York: United Nations, Department of Economic and Social Affairs.

United Nations. (2015). World population prospects: 2015 revision. New York: United Nations, Department of Economic and Social Affairs.

Vaupel, J. (1998). Demographic analysis of aging and longevity. The American Economic Review, 88(2), $242-247$.

Vaupel, J. (2010). Biodemography of human ageing. Nature, 464, 536-542.

Vaupel, J. M., \& Jeune, B. (1995). The emergence and proliferation of centenarians. In B. Jeune \& J. W. Vaupel (Eds.), Exceptional longevity: from prehistory to present. odense monographs on population ageing 2. Odense: Odense University Press.

Westendorp, R. G. J. (2004). Are we becoming less disposable? EMBO Reports, 5(1), 2-6.

Wilmoth, J. R. (1997). In search of limits: what do demographic trends suggest about the future of human longevity. In K. W. Wachter \& C. E. Finch (Eds.), Between Zeus and the Salmon (pp. 38-64). Washington DC: National Academy Press.

Wilmoth, J. R., \& Robine, J.-M. (2003). The world trend in maximum life span. Population and Development Review, 29, 239-257. 